\title{
Entrepreneurship and the Need for Sustainable New Technologies in Power Generation
}

\author{
Stephen Bani*, Sydney Abbey, Nii Quaynor, Emmanuel Adusei Essel \\ Faculty of Engineering, Accra Technical University, Accra, Ghana \\ Email: *sbani@atu.edu.gh
}

How to cite this paper: Bani, S., Abbey, S., Quaynor, N. and Essel, E.A. (2020) Entrepreneurship and the Need for Sustainable New Technologies in Power Generation. Energy and Power Engineering, 12, 641-652. https://doi.org/10.4236/epe.2020.1211038

Received: September 30, 2020

Accepted: November 20, 2020

Published: November 23, 2020

Copyright $\odot 2020$ by author(s) and Scientific Research Publishing Inc. This work is licensed under the Creative Commons Attribution International License (CC BY 4.0).

http://creativecommons.org/licenses/by/4.0/

\begin{abstract}
The increase of micro and nano devices has led to the miniaturization and multi-functionalization of micro-mechanical, communication, imaging, sensing, chemical analytical and biomedical devices. The devices so mentioned above need power sources that are portable, have short charging time, longevity, high energy density and are environmentally friendly. Chemical batteries hitherto used to be the major power source for these devices but have a drawback of having low energy density. The energy density of the most improved lithium-ion battery was in the region of $0.2 \mathrm{kWh} / \mathrm{kg}$. Micro-combustor is one of the most important components of the micro thermophotovoltaic (MTPV) conversion device. This work used numerical simulation to investigate the effect of Micro pin fin arrays on combustion. Using a micro combustor with micro pin-fin arrays inserted, it was observed the fins widened the region of combustion and extended the blow-off limit in the combustor. The fins exerted great influence on combustion as flow rate increased and thus improved the temperature distribution of the wall. The combustor with fins possessed higher heat flux in comparison with combustor without fins. There was combustion stability at inlet velocity of $4 \mathrm{~m} / \mathrm{s}$ making the micro pin-fin array configuration ideal for MTPV application. The results obtained will be useful in designing a MTPV.
\end{abstract}

\section{Keywords}

Entrepreneurship, Micro-Thermophotovoltaic, Micro Combustion, Numerical Simulation

\section{Introduction}

Micro-scale combustion has gained more and more attention as a kind of energy supply unit which is stable, lasting and small scaled [1] [2]. However, there are 
two problems associated with the reduction of the combustor size. One is that every fuel has a scale limit for combustion. The scale limit is the height as in planar micro combustors or diameter in cylindrical channel. The unstable combustion, and even extinction, appears when the height of the channel is close to the scale limit [3] [4] [5]. Surface to volume ratio is the other problem encountered as the combustor size is reduced. This leads to enormous heat loss.

A lot of research works, theoretical, numerical and experimental analysis have been done on micro combustors in a bid to scale down the heat loss and enhance the stability of the flame. Federici and Vlachos [6] came up with a micro combustor in a single-pass heat recirculation with the aim of mitigating the effect of heat loss and sustain the flame in the combustor. They concluded that, the recirculated heat affected the blow-off limit as a result of pre-heating the incoming flow and at the same time have less effect on flame extinction. Jiaqiang et al. [7] suggested a different micro combustor for non-premixed hydrogen-air combustion. They studied the mixing performance of the hydrogen-air in the micro combustor. Porous media combustion has also been suggested to enhance flame stability and attain higher conversion efficiency as compared to free flame combustor [8] [9] [10]. Pan et al. [11] studied the impact of key parameters on micro combustion in a combustor filled with porous media. They concluded that the porous media material having low specific heat and high thermal conductivity gives better temperature distribution on the wall. Another means of extending the flammability limit and thus improvement of flame stability is the addition of catalyst. Pan et al. [12] conducted a test to investigate the role of intermediate and final product from heterogeneous reactions on the homogeneous combustion in a catalytic combustor. Their research concluded that combustor performance is greatly enhanced in the hetero/homogeneous combustion due to existence of catalysis.

Waitz et al. [13] showed that early combustion in small spaces could be achieved under proper wall conditions. Some countries have developed and patented research in High Temperature Air Combustion (HTAC) [14] [15]. Leaning on the earlier experimental studies of Zamashchikov [16] [17], the method of environment heating to reduce heat loss, the quenching diameter proved to be smaller. Ochoa [18] after designed Swiss-roll combustor using bismuth telluride $\left(\mathrm{Bi}_{2} \mathrm{Te}_{3}\right)$ to reduce the heat loss through preheating the reactant between the influx and exhaust of the gas. Kaoru Maruta [19] observed the phenomenon of external heat in the quartz glass tube with a diameter of $2.0 \mathrm{~mm}$, and concluded that, the flame showed fluctuation and other special dynamic phenomena

Although a variety of improved combustion approaches have been reported in literature, simple yet effective methods are still desirable to widen the stable operating range of combustion-based micro-power generation systems. It is well known that micro-combustor with a bluff body or a backward facing step chamber is extensively used for flame stabilization.

Combustors having fins inserted increase heat transfer process via the walls and prolong residence time by gathering the reactants and making combustion 
efficient and improving stability of combustion. The micro pin-fin arrays are composed of fins that extend from one base area of the channel and the other wall of the channel serves as a barrier. The sole aim is obtaining uniform temperature distribution for MTPV application. A lot of researchers have experimentally and numerically investigated enhancing heat transfer by employing flow inducing vibration of micro-fins. Peles et al. [20] studied on micro pin fins with much emphasis on pressure drop and characteristics of the heat transfer. They optimized the geometrical and thermo-hydraulic parameters to bring down the system's total thermal resistance. They proved the thermal working of the micro-scale pin fin heat sink gives a low thermal performance and as such the configuration having sparse and dense pin fins can decrease system total thermal resistance. Kosar et al. [21] investigated by experiment and obtained fiction factor over intermediate size pin fins. They portrayed variations in long tube correlations if Reynolds number and fin height to diameter ratios are low.

In this paper, a new type of micro planar combustor with micro-pin-fin arrays was investigated by simulation method. Combustors with and without micropin-fin arrays were compared and their effects were analyzed. The characteristics of heat transfer and combustion in the micro-combustor of premixed hydrogen-air was obtained by changing some important structure parameters, so as to provide some valuable reference for further optimization.

In this paper, simulation of hydrogen-air combustion in a micro combustor is presented in the configurations, where micro obstacles are embedded in the combustor in the form of micro pin-fin arrays with the idea of enhancing combustion and heat transfer efficiency in the system. Combustors are critical in the design of MTPV systems and combustion stability is critical in the enhancement of the performance of the system. It has been discussed in literature that, combustors with fins possesses much higher surface temperature and heat flux than combustors without fins [22].

In order to further study the influence of fins on the micro-combustion heat transfer and combustion characteristics, the combustion of hydrogen/air in a micro-combustor with different fin arrangements was investigated by numerical simulation.

\section{Numerical Models and Simulation Approach}

The design of the combustor having micro pin-fin arrays are shown in Figure 1. Its structure is rectangular and eight micro-fins arrays are inserted in the combustor. The channel of the micro combustor has the following dimensions: length $(\mathrm{L})=25 \mathrm{~mm}$, width $(\mathrm{W})=20 \mathrm{~mm}$ and height $(\mathrm{H})=3 \mathrm{~mm}$ in the $\mathrm{x}, \mathrm{y}$ and $\mathrm{z}$ directions respectively. The thickness of the wall is $0.5 \mathrm{~mm}$. The inserted fins have the following dimensions: length $(\mathrm{L})=1 \mathrm{~mm}$, width $(\mathrm{W})=20 \mathrm{~mm}$ and a height $(\mathrm{H})=0.5 \mathrm{~mm}$. The material of the combustor and the fins was the $316 \mathrm{~L}$ stainless steel as it can withstand high temperatures. The coordinates have their origin at the channel entrance and here premixed $\mathrm{H}_{2}$ /air flow into the channel.

These assumptions were made in coming up with the model: 
1) Steady and laminar flow;

2) No thermo-physical properties variation with temperature;

3) Fluid is incompressible, Newtonian and viscous;

4) No velocity slips on the walls.

The hexahedral mapped mesh was adopted at three different mesh densities to improve the convergence speed and computation accuracy. A 3D computational model was developed and mesh independence test was undertaken. As indicated in Figure 2, the temperature profile of the mesh with the size $(102,000$ cells) has the highest wall temperature and for this reason, the mesh with $0.5,0.5$ and 0.1 $\mathrm{mm}$ was selected. The viscous model is laminar for the low velocity, and under uncertain flow regime SST $k-\omega$ model was selected. For the specific heat of species calculation, a piecewise polynomial fitting method was used. Incompressible ideal gas law and mixing law was used for the calculation of density and specific heat of $\mathrm{H}_{2}$ /air mixture. The thermal conductivity and viscosity of the gas mixture were calculated as mass fraction weighted average of all species. The kinetic theory was chosen to handle mass diffusivity calculation of mixture whiles SIMPLE algorithm was selected to handle the pressure velocity coupling. The convergence of simulation was declared when all governing equations of residuals approached steady state. The results reported in this work were achieved with residuals less than $10^{-6}$.

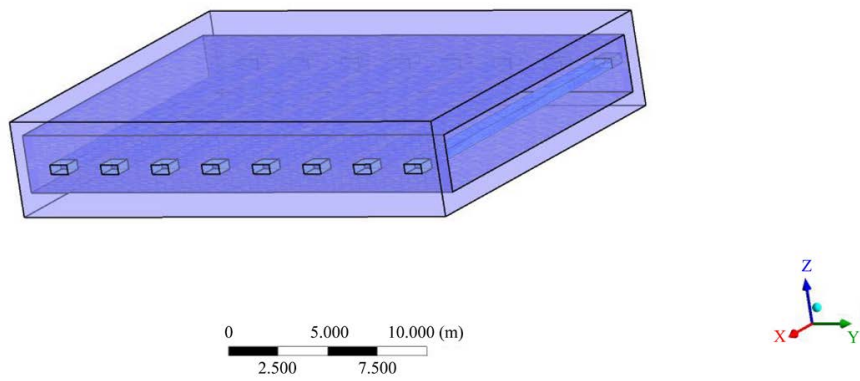

Figure 1. Schematic of micro combustor with micro-pin-fin arrays.

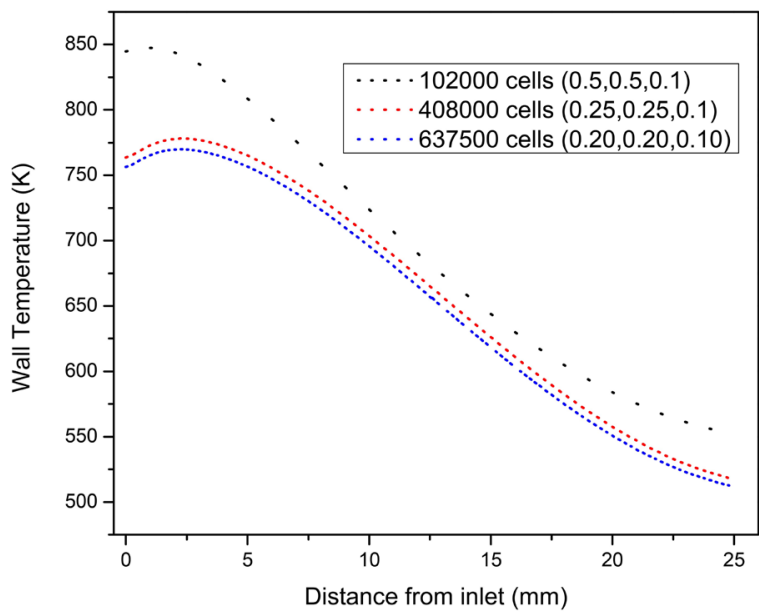

Figure 2. Temperature profiles at centerline of combustor wall at different mesh densities. 
The boundary conditions are set as follows. The mass-flow-inlet and outflow boundary conditions were specified at the inlet and outlet respectively. Different velocity profiles were adopted at the inlet, and the hydrogen-air equivalence ratio $(\phi)$ was 1.0 . In this work, the atmospheric pressure $(101 \mathrm{kPa})$ and temperature $(300 \mathrm{~K})$ were specified. The inlet temperature and initial temperature at the combustor walls were fixed at $300 \mathrm{~K}$. A skeletal gas phase reaction mechanism proposed by Giovangigli et al. [23] for $\mathrm{H}_{2}$ /air mixture was used in the computational domain. It is made up of 9 species and 19 reversible elementary reactions.

\section{Results and Discussions}

\subsection{Comparing Combustor with and without Micro Pin-Fin Array}

\subsubsection{Temperature and Velocity Field Distribution}

To verify the role of the micro pin-fin arrays in the MTPV set up, a comparative analysis of the combustor with the micro pin-fins and one without the fins inserted was made. The results regarding the flow field will be qualitatively analyzed using the bi-dimensional streamline average approach. Figure 3 shows the temperature distribution contour with the combustor with fins and one without fins. It can be observed that, the mean wall temperature for the combustor without fins was $1265 \mathrm{~K}$ whiles that of the combustor with fin was $1345 \mathrm{~K}$ at an inlet velocity of $6 \mathrm{~m} / \mathrm{s}$. The schematic diagram of the flow field of combustor with fins is shown in Figure 4 and it proves the formation of high temperature reflow zones are behind the fins. This phenomenon is explained by Bernoulli's equation which states there is sharp contraction of cross sectional area of combustor having lower pressure and high velocity when air flows through the fins. This results in two recirculation zones in maintaining a high temperature in the combustion area.

Figure 5 depicts the role the fins play on velocity field in the micro combustor. The velocities chosen were $2 \mathrm{~m} / \mathrm{s}, 4 \mathrm{~m} / \mathrm{s}, 6 \mathrm{~m} / \mathrm{s}$ and $8 \mathrm{~m} / \mathrm{s}$ and it is obvious the fins changed the distributions in the flow field. At a flow rate of $4 \mathrm{~m} / \mathrm{s}$, low velocity zone is seen after the fins and this obviously improved airflow resistance in the channel. This is beneficial to increase the residence time of airflow in the combustor with the view of improving combustion efficiency. At an inlet velocity greater or equal to $6 \mathrm{~m} / \mathrm{s}$, there is intensity of waves behind the fins at the low velocity zones and the high temperature reflow zone appears in the second column. Comparison of the mean wall temperatures of the external wall for different inlet velocities are shown in Figure 6 and the role the fins play on combustion reaction is analyzed. It is observed the mean temperature of the external wall increases with increase in the inlet velocity. Increment in the inlet velocity from $2 \mathrm{~m} / \mathrm{s}$ to $4 \mathrm{~m} / \mathrm{s}$ recorded an increase in mean wall temperature as $122.5 \mathrm{~K}$. Also, when the temperature increases from $6 \mathrm{~m} / \mathrm{s}$ to $8 \mathrm{~m} / \mathrm{s}$, the increment in temperature is $19 \mathrm{~K}$. This is because at a flow rate less than $6 \mathrm{~m} / \mathrm{s}$, there is significant advancement in the micro combustor as a result of the fins. Figure 4 shows the temperature profile of center section of the combustor with fins. When the flow rate is $2 \mathrm{~m} / \mathrm{s}$, most of the thermal energy in the combustor is in front of the 
combustor which makes the temperature decreases remarkably when the position shifts downstream.

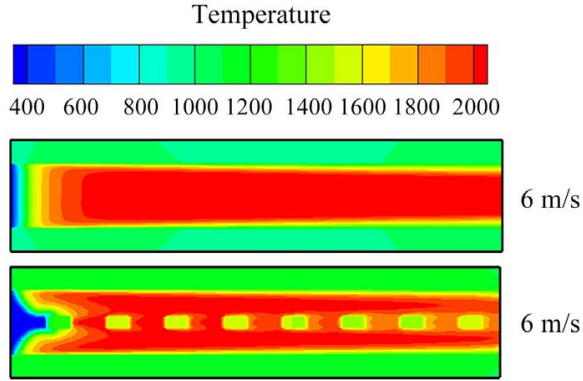

Figure 3. Temperature distribution of the case phi $=$ 1.0 at the rate of $6 \mathrm{~m} / \mathrm{s}$.

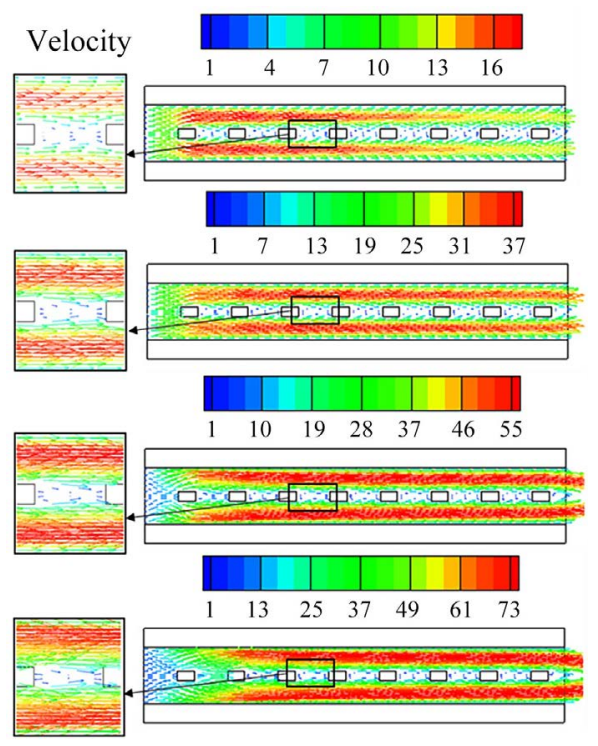

Figure 4. Velocity field distributions on the center section at different inlet velocities.

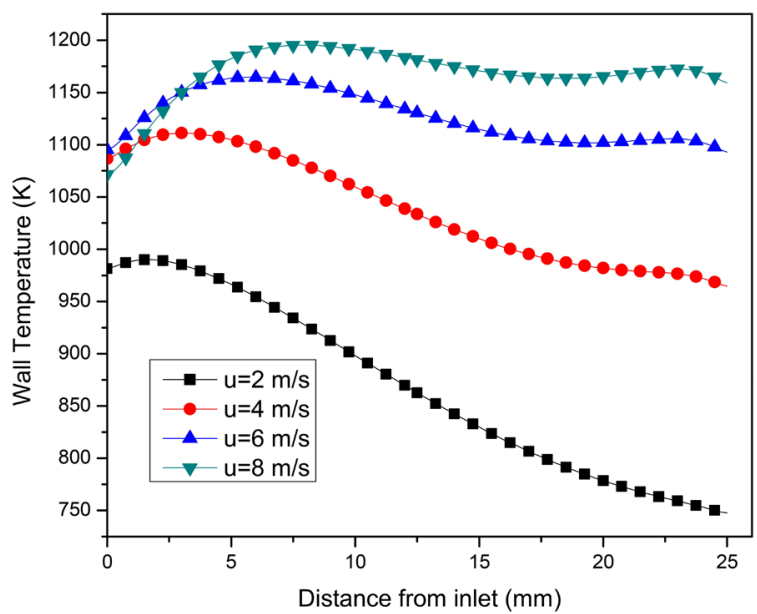

Figure 5. Centerline of wall temperature distributions at different inlet velocity. 


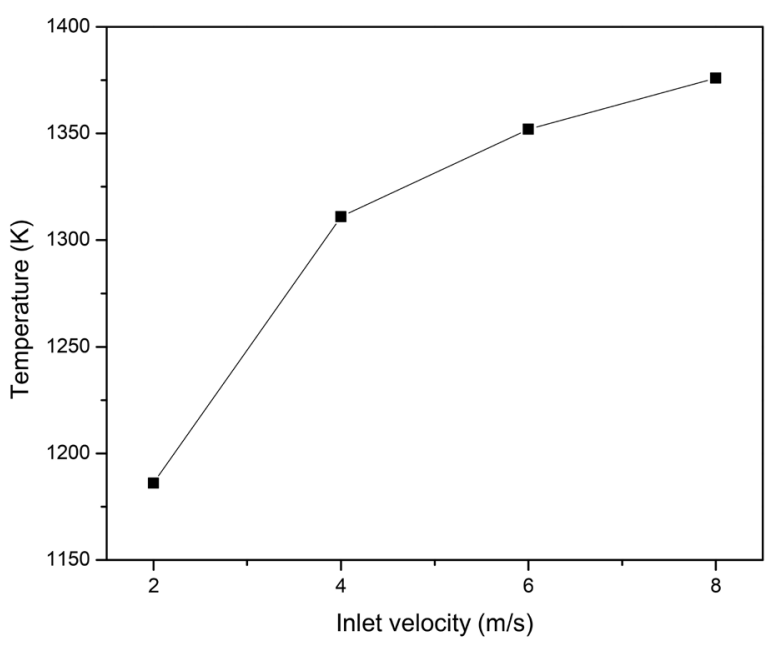

Figure 6. Outer wall mean temperature at different inlet velocities.

With increment in the flow rate, it is worth noting surface temperature of the combustor also increased rapidly and then decreased slowly, with the value of peak temperature outside the inlet. This implies the more the mixture flow rate, more fuel will participate in combustion giving high mean wall temperature. It is worth noting that, the maximum wall temperature of combustor with fins recorded $110 \mathrm{~K}$ higher than combustor without fin. This suggests that the fins improves heat transfer between fuel and the wall due to the fact that the low velocity zone after fins increases fuel residence time. The Dunkel number in this case is increased leading to an improvement in combustion efficiency, and the average wall temperature is enhanced. At $8 \mathrm{~m} / \mathrm{s}$ flow rate, it tends to be mild in the successive distances. We can infer from the distribution of temperature that, there is uniform and high temperature distribution with micro combustors with fins at high flow rates. It is therefore concluded that, the fin arrays does not only enhances the temperature of the wall but it reduces the difference in wall temperature distribution which is an important requirement for micro TPV application.

\subsubsection{Combustion Characteristics}

Figure 7 represents the hydroxyl $(\mathrm{OH})$ distribution at alternative inlet velocities. The $\mathrm{OH}$ is a representation of the position of the flame. It can be seen from the figure that the arrangement of the fins have little effect on the flame position but have influence on the shape of the flame. The combustion reaction for the inlet velocity of $2 \mathrm{~m} / \mathrm{s}$ is mostly concentrated at the inlet. This is as a result of increase in blockage ratio and is defined as the ratio of the maximum cross sectional area to the cross sectional area of the obstacle in the direction of flame propagation. As the flow rate increases, there is increment in the effect of fins on combustion. It is as a result of shear force on both sides of the fins.

It is obvious that, with combustors with fins, the flame deformation is obvious under the effect of the fin arrays. The fins do not only promote combustion reaction, but also increase the blow off limit. Similar results were reported by 


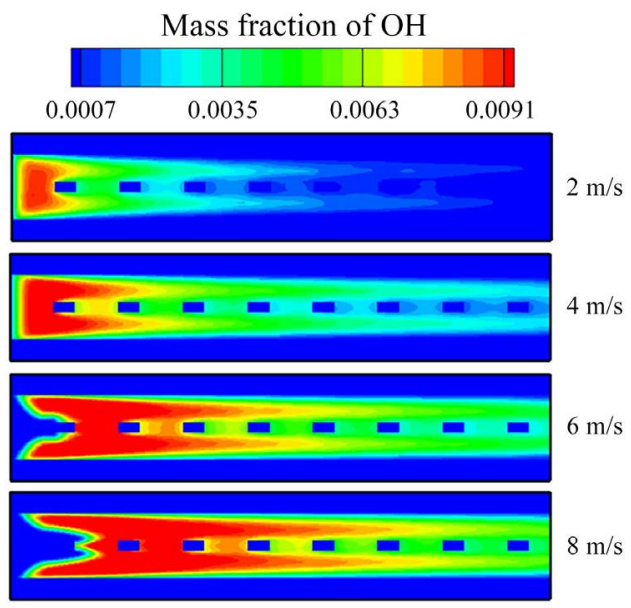

Figure 7. Concentration field profile on the center section of three combustors at different inlet velocities.

Zhu et al. [24]. The fins in the combustor, just like the combustor with bluff body play a significant role in promoting and stabilizing combustion. This is because the probability of collision between the key components of the chain reaction like $\mathrm{OH}$ and the wall in the combustors with fins are less as compared to that without fins. The probability of capturing free radicals is less in combustors with fins than those without fins. Similar results were reported by [25] [26]. It can be observed from the $\mathrm{OH}$ distribution that, there is sharp increment in the $\mathrm{OH}$ mass fraction but this gradually decreases. The peak value of the $\mathrm{OH}$ mass fraction appears at points away from the inlet where the gas gets to the fins. As a result of the arrangement of the fins along the direction of flow, the gas is capable of flowing at both sides of the fin. This makes the combustion reaction to head towards the upper wall making it possible for the $\mathrm{OH}$ concentration to increase at the fins. This occurrence is more obvious with large flow velocities as a result of the shear forces on both sides of the fin.

A characteristic of micro combustors is that, at velocities specifically $4 \mathrm{~m} / \mathrm{s}$ and $6 \mathrm{~m} / \mathrm{s}$, the fins leave an important mark on the combustion characteristics. The advantageous role the fins play diminishes at flow velocities of $8 \mathrm{~m} / \mathrm{s}$ as a result of hydrogen being a flammable gas. Due to the large blockage ratio for combustors with fins, it turns out that combustors without fins display higher hydrogen conversion ratio. As the flow rate increases, the hydrogen conversion ratio becomes weaker. The combustor with fins recorded the highest hydrogen conversion ratio at a flow rate of $4 \mathrm{~m} / \mathrm{s}$. This is as a result of the fact that, combustors have small volume making it impossible for the fuel to have complete combustion under large inlet velocities.

\subsubsection{Thermal Characteristics}

Figure 8 is the heat flux of external wall at different inlet velocities. The mean wall temperature and heat flux of the external wall show similar trends. This is because the heat flux of the external wall is directly proportional to the mean temperature of the wall and is given as: 


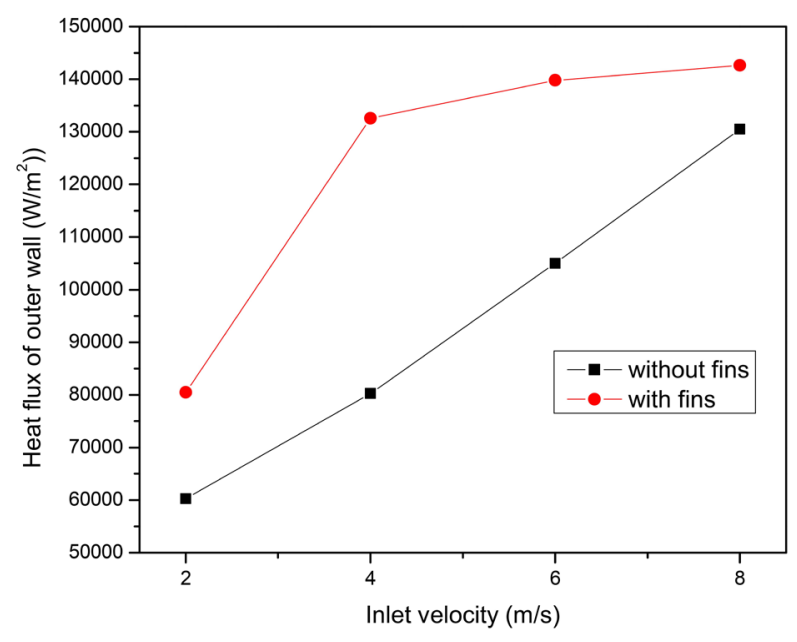

Figure 8. Average external wall heat flux at different inlet velocities.

$$
q_{w}=k \frac{\left(T_{w}-T_{\infty}\right)}{L} g(\operatorname{Re}, \operatorname{Pr})
$$

where $k$ is the thermal conductivity; $L$ is the characteristic length of an object, $\mathrm{mm} ; T_{w}$ is the external wall mean temperature, $K ; T_{\infty}$ is the environment temperature, $K ; g$ is the dimensionless function; Re is the Reynolds number; $\operatorname{Pr}$ is the Prandtl number.

From Figure 8 it can be seen that, there is vast difference in the mean heat flux between the combustor with fins and that without fins. It can be observed that, the mean heat flux increases with increment in inlet velocity. As the flow rate hits the $8 \mathrm{~m} / \mathrm{s}$ mark, the level of heat transfer intensity by the fins is not as much as observed earlier. A conclusion can be adduced from the heat transfer coefficient as a function of the wall thermal conductivity for the combustor as revealed in Figure 9. At a flow rate up to $8 \mathrm{~m} / \mathrm{s}$, there is increase in the average surface heat transfer coefficient and it is because of the high blockage ratio of the combustor having fins at high inlet velocities resulting in low heat transfer process. It presupposes that, at high flow rate, blockage ratio affects temperature which intend interfere with heat transfer coefficient.

\section{Conclusions}

Heat transfer and flow field characteristics of a micro combustor with micro pin-fins were investigated using numerical methods. The simulated results were compared with experimental results and there was good agreement between experiment and simulation results. The following conclusions were obtained:

1) Increase in the flow rate intensifies the degree of chaotic waves in the low velocity zones behind the fins with the high temperature reflow zone appearing farther from the inlet.

2) The fins widen the region of combustion and also extend the blow off limit. This thus improves the temperature of the walls. The fins had great influence on combustion as the flow rate increased. 


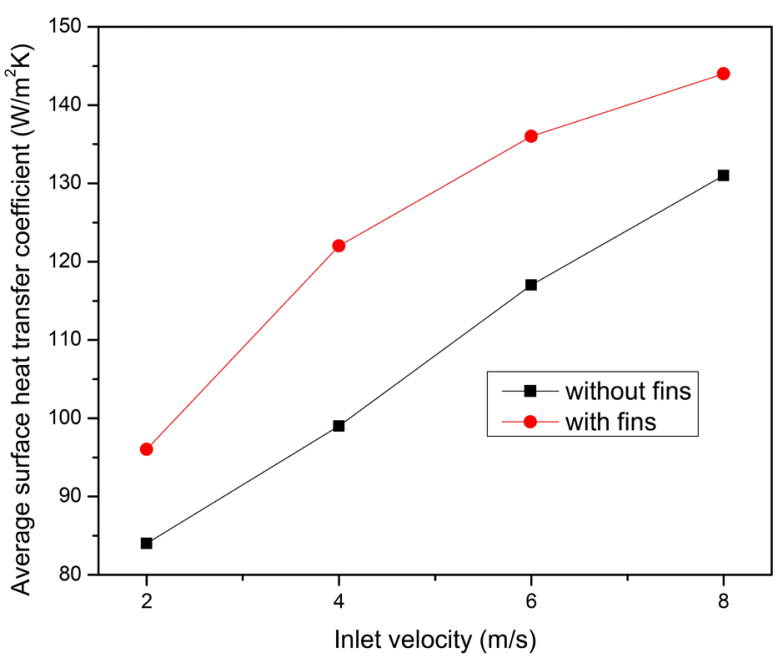

Figure 9. Average surface heat transfer coefficient at different inlet velocities.

3) Heat flux of outer wall of the combustor with fins is higher compared with combustor without fins. Both observed increment in value of the heat flux as flow velocity increased.

4) The combustor with fins has great effect on heat transfer between inner walls of combustor and gas. There is therefore combustion stability at the inlet velocity of $4 \mathrm{~m} / \mathrm{s}$. This thus enhanced the temperature of the wall and ideal for Micro-TPV power generation.

\section{Acknowledgements}

The authors acknowledge research support from Accra Technical University.

\section{Conflicts of Interest}

The authors declare no conflicts of interest regarding the publication of this paper.

\section{References}

[1] Maruta, K. (2011) Micro and Mesoscale Combustion. Proceedings of the Combustion Institute, 33, 125-150. https://doi.org/10.1016/j.proci.2010.09.005

[2] Chou, S., Yang, W., Chua, K., Li, J. and Zhang, K. (2011) Development of Micro Power Generators-A Review. Applied Energy, 88, 1-16. https://doi.org/10.1016/j.apenergy.2010.07.010

[3] Alliche, M., Haldenwang, P. and Chikh, S. (2010) Extinction Conditions of a Premixed Flame in a Channel. Combustion and Flame, 157, 1060-1070. https://doi.org/10.1016/j.combustflame.2010.02.006

[4] Maruta, K., Takeda, K., Ahn, J., Borer, K., Sitzki, L., Ronney, P.D., et al. (2002) Extinction Limits of Catalytic Combustion in Microchannels. Proceedings of the Combustion Institute, 29, 957-963. https://doi.org/10.1016/S1540-7489(02)80121-3

[5] Yang, W., Fan, A., Wan, J. and Liu, W. (2015) Effect of External Surface Emissivity on Flame-Splitting Limit in a Micro Cavity-Combustor. Applied Thermal Engineering, 83, 8-15. https://doi.org/10.1016/j.applthermaleng.2015.03.009 
[6] Federici, J. and Vlachos, D. (2008) A Computational Fluid Dynamics Study of Propane/Air Microflame Stability in a Heat Recirculation Reactor. Combustion and Flame, 153, 258-269. https://doi.org/10.1016/j.combustflame.2007.09.009

[7] Jiaqiang, E., Peng, Q., Zhao, X., Zuo, W., Zhang, Z. and Pham, M. (2017) Numerical Investigation on the Combustion Characteristics of Non-Premixed Hydrogen-Air in a Novel Micro-Combustor. Applied Thermal Engineering, 110, 665-677. https://doi.org/10.1016/j.applthermaleng.2016.08.210

[8] Mujeebu, M.A., Abdullah, M.Z., Bakar, M.A., Mohamad, A. and Abdullah, M. (2009) Applications of Porous Media Combustion Technology-A Review. Applied Energy, 86, 1365-1375. https://doi.org/10.1016/j.apenergy.2009.01.017

[9] Sanmiguel, J.E., Mehta, S.R. and Moore, R.G. (2003) An Experimental Study of Controlled Gas-Phase Combustion in Porous Media for Enhanced Recovery of Oil and Gas. Journal of Energy Resources Technology, 125, 64-71.

https://doi.org/10.1115/1.1510522

[10] Bani, S., Pan, J., Tang, A., Lu, Q. and Zhang, Y. (2017) Micro Combustion in a Porous Media for Thermophotovoltaic Power Generation. Applied Thermal Engineering. https://doi.org/10.1016/j.applthermaleng.2017.10.024

[11] Pan, J., Huang, J., Li, D., Yang, W., Tang, W. and Xue, H. (2007) Effects of Major Parameters on Micro-Combustion for Thermophotovoltaic Energy Conversion. Applied Thermal Engineering, 27, 1089-1095. https://doi.org/10.1016/j.applthermaleng.2006.07.038

[12] Pan, J., Wu, D., Liu, Y., Zhang, H., Tang, A. and Xue, H. (2015) Hydrogen/Oxygen Premixed Combustion Characteristics in Micro Porous Media Combustor. Applied Energy, 160, 802-807. https://doi.org/10.1016/j.apenergy.2014.12.049

[13] Waitz, I.A., Gauba, G. and Tzeng, Y.-S. (1996) Combustors for Micro-Gas Turbine Engines.

[14] Yoshikawa, K. (1999) Gasification and Power Generation from Solid Fuels Using High Temperature Air. Proceeding of High Temperature Air Combustion Symposium, 68.

[15] Gupta, A., Bolz, S. and Hasegawa, T. (1999) Effect of Air Preheat Temperature and Oxygen Concentration on Flame Structure and Emission. Journal of Energy Resources Technology, 121, 209-216. https://doi.org/10.1115/1.2795984

[16] Zamashchikov, V. (1997) Experimental Investigation of Gas Combustion Regimes in Narrow Tubes. Combustion and Flame, 108, 357-359.

https://doi.org/10.1016/S0010-2180(96)00169-1

[17] Zamashchikov, V. (2001) An Investigation of Gas Combustion in a Narrow Tube. Combustion Science and Technology, 166, 1-14.

https://doi.org/10.1080/00102200108907817

[18] Ochoa, F., Eastwood, C., Ronney, P. and Dunn, B. (2003) Thermal Transpiration Based Microscale Propulsion and Power Generation Devices. Seventh International Workshop on Microgravity Combustion and Chemically Reacting Systems, 373.

[19] Maruta, K., Kataoka, T., Kim, N.I., Minaev, S. and Fursenko, R. (2005) Characteristics of Combustion in a Narrow Channel with a Temperature Gradient. Proceedings of the Combustion Institute, 30, 2429-2436. https://doi.org/10.1080/00102200108907817

[20] Peles, Y., Koşar, A., Mishra, C., Kuo, C.J. and Schneider, B. (2005) Forced Convective Heat Transfer across a Pin Fin Micro Heat Sink. International Journal of Heat \& Mass Transfer, 48, 3615-3627.

https://doi.org/10.1016/j.ijheatmasstransfer.2005.03.017 
[21] Kosar, A., Mishra, C. and Peles, Y. (2005) Laminar Flow across a Bank of Low Aspect Ratio Micro Pin Fins. Journal of Fluids Engineering, 127, 419-430.

https://doi.org/10.1115/1.1900139

[22] Go, J.S., Kim, S.J., Lim, G., Yun, H., Lee, J., Song, I., et al. (2001) Heat Transfer Enhancement Using Flow-Induced Vibration of a Microfin Array. Sensors \& Actuators A Physical, 90, 232-239. https://doi.org/10.1016/S0924-4247(01)00522-2

[23] Giovangigli, V. and Smooke, M.D. (1987) Extinction of Strained Premixed Laminar Flames with Complex Chemistry. Combustion Science \& Technology, 53, 23-49. https://doi.org/10.1080/00102208708947017

[24] Pan, J., Zhu, J., Liu, Q., Zhu, Y., Tang, A. and Lu, Q. (2017) Effect of Micro-Pin-Fin Arrays on the Heat Transfer and Combustion Characteristics in the Micro-Combustor. International Journal of Hydrogen Energy, 42.

https://doi.org/10.1016/j.ijhydene.2017.06.164

[25] Nair, S. and Lieuwen, T.C. (2007) Near-Blowoff Dynamics of a Bluff-Body Stabilized Flame. Journal of Propulsion \& Power, 23, 421-427. https://doi.org/10.2514/1.24650

[26] Bakrozis, A.G., Papailiou, D.D. and Koutmos, P. (1999) A Study of the Turbulent Structure of a Two-Dimensional Diffusion Flame Formed Behind a Slender BluffBody. Combustion \& Flame, 119, 291-306.

https://doi.org/10.1016/S0010-2180(99)00061-9 